\title{
Emotional Distress During Internship: Causes and Support Systems
}

\author{
D. Michael Elnicki, MD \\ Department of Medicine, University of Pittsburgh Pittsburgh, PA, USA.
}

$\mathrm{J}$ Gen Intern Med 35(12):3434-5

DOI: $10.1007 / \mathrm{s} 11606-020-06283-2$

(c) Society of General Internal Medicine 2020

$\mathrm{M}$ any physicians experience emotional distress during medical training. In this issue of JGIM, Moore and colleagues $^{1}$ expand our understanding of the problem with a thoughtful study of interns' emotional distress and the support they do or do not receive. We know from prior research that emotional distress and burnout are common early in medical careers. ${ }^{2,}{ }^{3}$ Physician distress has real consequences that are not limited to the distressed physician. Studies of burnout have shown higher rates of unprofessional behaviors, ${ }^{4}$ lower markers of achievement, ${ }^{5}$ and the self-perception of delivering poorer patient care ${ }^{6}$ in affected physicians and trainees.

Using qualitative methods, the authors outline the causes of interns' distress. First, they define chronic, "contextual factors," many of which are systems issues. These markers of dysfunctional work environments remain pervasive in medical education, in spite of efforts to reform the internship experience, and they can gradually wear down the interns. Then authors describe how interns are then hit with "acute triggers" encountered during patient care. These triggers include caring for very ill or difficult patients and dealing with patients' deaths. This "double hit" combination can push an intern over the emotional brink and into a distressed state.

Having examined the causative factors, the authors then describe efforts made by senior residents to mitigate the suffering they observe in their junior colleagues. Often, these are small gestures, such as a kind word or holding a pager. We do remember these acts of kindness. While writing this, I recalled as an intern arriving beleaguered to a general medicine ward rotation after a hard month in the cardiac intensive care unit. My resident, now a prominent academic, looked me over and then wrote all my notes as I acquainted myself with the patients on the service. He then took me out for beers and a game of darts after sign out. Refreshed, I charged into the service on the following day. These gestures may be the most memorable and easiest to articulate, but one wonders what else the residents are doing to support interns they see as struggling emotionally. Some actions, no matter how well intentioned, may not be helpful. Furthermore, by acting alone, residents

Published online October 7, 2020 may neglect to refer a struggling intern to someone better prepared to assist.

That interns receive emotional support from their residents is understandable, since the residents are physically present and support the interns in numerous other ways. Residents serve as role models, define expectations, establish the learning environment, provide experiential learning, give feedback, and stimulate independent learning. ${ }^{7}$ What remains predictably disappointing is the lack of institutional support. The interns and residents are struggling through crises using ad hoc solutions. Many of the residents' actions were based on the idiosyncratic experiences that the residents themselves had experienced as interns.

The explanations given by Moore and colleagues of interns' distress seem plausible, and their call for programmatic support via training residents how better to support their interns follows logically. That interns need assistance at the programmatic level stems from their low level in the medical hierarchy. Many of the defined sources of resiliency, such as access to leisure activities and the ability to limit their own working hours, ${ }^{8}$ are unavailable to them. Furthermore, trainees perceive stigma to exist if they do seek help for overwhelming situations. ${ }^{9}$ The interventions that the authors describe seem to be low intensity interventions for issues that can cause major disruptions in educational programs and in patient care. The simple, educational interventions that the authors outline could potentially do much to alleviate the problem. However, the program that they outline will need to be assessed for effectiveness prior to dissemination.

As Moore and colleagues mention, the final and most likely most difficult piece to solving the problem of distressed trainees is for training programs in both undergraduate and graduate medical education to effect preventive, systems-based changes. As long as trainees are overworked and isolated, they will become distressed. The absence of attending physicians in this discussion is striking. They are certainly more empowered than residents and are more experienced in dealing with crises like these. Attending physicians should lead the call for system changes. Real changes in our training systems will likely be costly and will be the most resisted. There is unlikely to be a single answer for training programs to adopt. New sources of distress will likely continue to arise. One example is the electronic medical record (EMR), which most thought would make physicians lives easier. Instead, EMR use has become associated with burnout and poor work-life balance. ${ }^{10}$ 
Therefore, improvements in interns', and other trainees', learning environments will need to be ongoing. Fundamental systems changes will require the buy in of academic and hospital systems leaders who will need to be convinced that such investments will pay both humanistic and productivity dividends.

Corresponding Author: D. Michael Elnicki, MD; Department of Medicine, University of Pittsburgh Pittsburgh, PA, USA (e-mail: dme101@pitt.edu).

\section{Compliance with Ethical Standards:}

Conflict of Interest: The author declares that he does not have a conflict of interest.

\section{REFERENCES}

1. Moore K.A., O'Brien B.C., Thomas L.R. "I wish they had asked": A qualitative study of emotional distress and peer support during internship. J Gen Intern Med. https://doi.org/10.1007/s11606-020-05803-4.

2. Hariharan, T. S., \& Griffin, B. A review of the factors related to burnout at the early-career stage of medicine. Med Teach. 2019;41(12):13801391.
3. Dyrbye L.N., et al. Burnout Among U.S. Medical Students, Residents, and Early Career Physicians Relative to the General U.S. Population. Acad Med. 2014;89(3):443-50.

4. Dyrbye L.N., et al. Relationship Between Burnout and Professional Conduct and Attitudes Among US Medical Students. JAMA. 2010;304(11):1173-80.

5. West C.P., Shanafelt T.D., Kolars J.C. Quality of Life, Burnout, Educational Debt, and Medical Knowledge Among Internal Medicine Residents. JAMA. 2011;306(9):952-60.

6. Shanafelt T.D., Bradley K.A., Wipf J.E., Back A.L. Burnout and SelfReported Patient Care in an Internal Medicine Residency Program. Ann Intern Med. 2020;136(5):358-66.

7. Karani R., et al. How Medical Students Learn From Residents in the Workplace: A Qualitative Study. Acad Med. 2014;89(3):490-6.

8. Zwack J., \& Schweitzer, J. If Every Fifth Physician Is Affected by Burnout, What About the Other Four? Resilience Strategies of Experienced Physicians. Acad Med. 2013;88(3):382-9.

9. Dyrbye L.N., et al. The Impact of Stigma and Personal Experiences on the Help-Seeking Behaviors of Medical Students With Burnout. Acad Med. 2015;90(7):961-8.

10. Robertson S.L., Robinson M.D., Reid, A. Electronic Health Records Effects on Work-Life Balance and Burnout Within the $\mathrm{I}^{3}$ Population Collaborative. J Grad Med Educ. 2017. 479-84. https://doi.org/10. 4300/JGME-D-16-00123.1.

Publisher's Note: Springer Nature remains neutral with regard to jurisdictional claims in published maps and institutional affiliations. 